\title{
AES, XPS AND TEM CHARACTERIZATION OF BORON NITRIDE DEPOSITED UNDER CHEMICAL VAPOR INFILTRATION (CVI) CONDITIONS
}

\author{
O. DUGNE, S. PROUHET, A. GUETTE, R. NASLAIN, R. FOURMEAUX* , K. HSSEIN ${ }^{\star}$ \\ J. SEVELY* ${ }^{*}$ C. GUIMON ${ }^{*}$, D. GONBEAU** and G. PFISTER-GUILLOUZO** \\ Laboratoire des Composites Thermostructuraux, UM 47, CNRS-SEP-UBI, \\ Europarc, 3, avenue Léonard de Vinci, F-33600 Pessac, France \\ "Laboratoire d'optique Electronique du CNRS, 29, rue Jeanne Marvig, \\ F-31055 Toulouse, France \\ * Laboratoire de Physico-Chimie Moléculaire, CNRS UA-474, Université de \\ Pau, 2, avenue Président Angot, F-64000 Pau, France
}

\begin{abstract}
RESUME
Des dépôts de nitrure de bore, élaborés à partir de mélanges gazeux $\mathrm{BF}_{3}-\mathrm{NH}_{3}$ dans des conditions CVI et déposés dans des préformes fibreuses ou sur des substrats plans de carbure de silicium ont été caractérisês par XRD, AES, XPS et TEM. Ces dépôts sont non stoechiométriques et possèdent du bore en excès $(\mathrm{N}: \mathrm{B}$ at $=0,6-0,8)$ ainsi qu'une quantité non négligeable d'oxygène. L'unité structurale de base se compose $d^{\prime}$ hexagones quasi parfaits. L'arrangement des couches est typiquement turbostratique $\left(d_{002}=3,64 \AA ; L_{C}=28 \AA\right)$. Ces empilements sont aléatoirement orientés au sein du dépôt mais tendent à s'orienter parallèlement à $1^{\prime}$ interface proche du substrat. Le dépôt comporte des pores submicroscopiques, une faible densité $\left(1,6-1,9 \mathrm{~g} \cdot \mathrm{cm}^{-3}\right) \mathrm{et}$ une certaine nanoporosité $(8-22 \%)$. La microstructure est semblable à celle du pyro-carbone élaboré dans des conditions similaires.
\end{abstract}

\section{ABSTRACT}

$\mathrm{BN}$-films deposited, from $\mathrm{BF}_{3}-\mathrm{NH}_{3}$ mixtures under CVI-conditions, either within porous SiC fiber preforms or on plan sintered SiC substrates, have been characterized, at a submicron scale, by XRD, AES, XPS and TEM. The deposits are nonstoichiometric with an excess of boron $(\mathrm{N}: \mathrm{B}$ at. $=0.6-0.8)$ and contain a significant amount of oxygen. The basic structural unit is an almost perfect hexagonal ring. The stacking of the hexagonal layers is turbostratic $\left(\mathrm{d}_{002}=3.64 \AA\right.$ ; $\mathrm{L}_{\mathrm{C}}=28 \AA$ ). The $\mathrm{BN}$ layers are randomly orientated in the bulk of the deposit but tend to be aligned parallel to the interface near the substrate surface. The deposit contains numerous submicroscopic pores. It has a low density $\left(1.6-1.9 \mathrm{~g} . \mathrm{cm}^{-3}\right)$ and a significant nanoporosity $(8-22 \%)$. The main features of the microstructure are similar to those of pyrocarbon deposits.

\section{INTRODUCTION}

Boron nitride obtained by chemical vapor deposition (CVD) has been used for many years in electronic devices and high temperature electrical engineering on the basis of its high electrical resistivity, high thermal conductivity and good chemical inertia /1/. In a different field, BN-based ceramic matrix composites (CMC), obtained by chemical vapor infiltration (CVI) of a porous preform made of ceramic fibers, have been suggested as an alternative to carbon-carbon for applications at high temperatures in air. As a matter of fact, hexagonal boron nitride has a crystal structure very similar to that of graphite, a high refractoriness and a better resistance towards oxidation (the oxidation of carbon in air begins at about $600^{\circ} \mathrm{C}$ whereas that of hex-BN takes place above $800-900^{\circ} \mathrm{C}$ ). In the first studies, the goal was to use boron nitride as a matrix $/ 2-6 /$.

More recently, the use of hex-BN as a coupling interphase between the fibers and the matrix, has been suggested for improving the toughness of CMC. It is now well established that the outstanding toughness (i.e. similar to that of light alloys) of fibrous CMC is directly related to weak fiber-matrix bonding (which allows fiber-matrix debonding/friction 
and fiber pull out phenomena absorbing energy and thus increasing the work of fracture and toughness). Regarding the high temperatures at which they are processed, CMC are normally characterized by a strong fiber-matrix bonding and a brittle behavior. Therefore, controlling the fiber-matrix bonding during processing is of key importance. One of the most effective way to weaken the fiber-matrix bonding in CMC is to introduce a mechanically soft material at the interface. It has been shown that pyrocarbon, with its layered structure fulfills this requirement /7-9/. However, in oxidizing environments the advantage of the pyrocarbon interphase is lost at high temperatures. The use of its boron nitride counterpart has been studied in a variety of SiC (Nicalon) fiber composites (the matrix being zirconia or zircon, mullite, glass-ceramics and silicon carbide) in order to keep high toughness values under severe environmental conditions (i.e. high temperatures and oxygen containing atmospheres) $/ 9-12 /$.

The aim of the present work was to characterize, from a physico-chemical standpoint, the structure and microstructure of the boron nitride, deposited under CVI-conditions, either on plan substrates or within porous fiber preforms, from a $\mathrm{BF}_{3}-\mathrm{NH}_{3}$ precursor according tó a process which has been described in details elsewhere /2/. The analyses of the BN deposits were performed by X-Ray Photoelectron Spectroscopy (XPS), Auger Electron pectroscopy (AES) and Transmission Electron Microscopy (TEM).

\section{EXPERIMENTAL}

The deposits which have been studied were obtained, under low pressure CVI-conditions, from $\mathrm{BF}_{3}-\mathrm{NH}_{3}$ gas mixtures (with an atomic $\mathrm{NH}_{3} / \mathrm{BF}_{3}$ ratio higher than one) at a temperature of about $950^{\circ} \mathrm{C}$. More details about the experimental conditions are given in $/ 2 /$.

The analyses were performed : (i) on fibers extracted from dry SiC (Nicalon) fiber preforms after they have been consolidated with a small amount of boron nitride by CVI (i.e. at a step corresponding to the deposition of the BN-interphase in the processing of SiC-SiC composites) and (ii) on plane sintered SiC (1) substrates which have been treated simultaneously.

Due to the dimensional difference between the space resolution of the XPS-apparatus (2) (i.e. about $150 \mathrm{\mu m}$ ) and the size of the SiC fibers (mean diameter : $15 \mu \mathrm{m}$ ), the XPS analysis were performed essentially on plane SiC substrate with BN deposits to have better reliability about chemical analyses and spectrum deconvolution. One analysis on $B N$ coated $\mathrm{SiC}$ fibers is also given. The Auger electron spectroscopy analyses (AES) were performed, with a microprobe (3) having a space resolution better than $1 \mu \mathrm{m}$, on both $\mathrm{BN}-\mathrm{coated} \mathrm{SiC}$ fibers and plane sintered SiC substrates, thus allowing a comparison with the results obtained by ESCA.

The transmission electron microscopy (TEM) experiments were run on thin foils prepared by ultramicrotomy from BN-coated SiC fibers. The chemical composition of the BN-deposits was determined by electron energy loss spectroscopy (EELS) whereas their structure and microstructure were studied by electron diffraction as well as by extended energy loss fine structure (EXELFS) after mathematical treatment of the EELS spectra (giving the radial distribution function (RDF) $i . e$. the surrounding in first neighbors of a given atom) /13/. Complementary structural data were obtained by conventional X-ray diffraction (XRD).

\section{RESULTS AND DISCUSSION}

\section{(1) Chemical composition}

As shown in fig. 1, the chemical composition of a BN-deposit obtained on a plane substrate under low pressure CVI-conditions is homogeneous but not stoichiometric (this being confirmed by XPS as it is apparent from table 1), the N:B atomic ratio ranging from 0.6 to 0.7 . The same result is also deduced for boron nitride deposited on SiC fibers, on the basis of EELS analyses $(\mathrm{N}: \mathrm{B}=0.7-0.8)$ of spectra similar to that of fig. 2 . Therefore, there is a good agreement between the experimental data whatever the morphology of the substrates on which BN was deposited and the analytical method. It is noteworthy that

(1) from Ceramiques et Composites, (2) SSI 301, (3) PHI-590, (4) PHILIPS EM $400 \mathrm{~T}$ 
a similar non-stoichiometry has been also reported by G. Lacrambe for boron nitride deposited under close CVI-conditions from $\mathrm{BCl}_{3}-\mathrm{NH}_{3}$ gas mixtures within porous fiber preforms 16/. Therefore, a low nitrogen concentration (with respect to stoichiometric BN) seems to be a general feature of the BN-deposits obtained from $\mathrm{BX}_{3}-\mathrm{NH}_{3}$ mixtures (with $\mathrm{X}=\mathrm{F}, \mathrm{Cl}$ ) at low temperature and pressure.

Furthermore and as shown in fig. 1-2 and table 1, there is a significant amount of oxygen (i. e. $10-15 \%$ at.) in the BN deposits obtained by CVI from $\mathrm{BF}_{3}-\mathrm{NH}_{3}$. As shown in fig. 3, the deconvolution of the $B$ 1s peak obtained by XPS suggests the occurrence of two different kinds of chemical bonding involving boron atoms : (i) that characteristic of hex$\mathrm{BN}$ (at $190,2 \mathrm{eV}$ ) and (ii) an additional chemical bonding (at $191.6 \mathrm{eV}$ ) which could correspond to a boron atom simultaneously bonded to oxygen and nitrogen, on the basis of the binding energies reported for $\mathrm{B} 1 \mathrm{~s}$ in $\mathrm{B}_{2} \mathrm{O}_{3}(193.5 \mathrm{eV})$ and hex-BN $(190.3 \mathrm{eV})$.

This shift of the B 1s binding energy related to the presence of oxygen in hex-BN has been already mentioned by V.G. Aleshin et al. (binding energy : $191.6 \mathrm{eV}$ for 11 at. \% oxygen) and G. Lacrambe (binding energy : $192.5 \mathrm{eV}$ for oxygen atomic concentrations higher than $20 \%) / 6,14 /$. The B 1s binding energy shift, which is observed when the oxygen concentration is increased, suggests that oxygen is present within the crystal network (possibly in nitrogen vacancies, regarding the low $\mathrm{N}$ : $\mathrm{B}$ ratio mentioned above ; table I) and has been introduced in the material at high temperatures during the film deposition processing.

\section{2- Texture and microstructure}

As a matter of fact, few studies have been devoted in the past to the characterization by TEM of hex-BN deposits. As a result, their texture and microstructure remained poorly known up to now.

On the basis of the results of the present study, it appears that the BN films, deposited from $\mathrm{BF}_{3} \mathrm{NH}_{3}$ mixtures, exhibit the main features already reported for pyrocarbon deposits obtained at low temperatures (fig. 4) /15/. The material is made of stacks of turbostratic BN layers highly curved and contains numerous submicroscopic pores (mean diameter : $5-8 \mathrm{~nm}$; shell thickness : $4-12 \mathrm{~nm}$ ). In the very vicinity of the fiber (i.e. within about $10 \mathrm{~nm}$ ), the BN layers have a tendency to be aligned parallel to the fiber surface whereas they are randomly orientated beyond this distance, as shown by the electron microdiffraction patterns (STEM configuration) given in inserts in $\mathrm{fig}$. $4 / 16 /$. Thus, the structure of $\mathrm{BN}$ in the deposits obtained from $\mathrm{BF}_{3}-\mathrm{NH}_{3}$ at about $950^{\circ} \mathrm{C}$ appears to be turbostratic.

The dhkl values as well as the mean thickness of the BN layers $\left(L_{c}\right)$ were derived from both XRD and electron diffraction patterns and are given in table 2. The low state of crystallization of the BN deposits obtained under CVI conditions is evidenced from the rather high $\mathrm{d}_{002}$ and low $\mathrm{L}_{\mathrm{c}}$ values. It is noteworthy that $\mathrm{H}$. Tagawa and $\mathrm{K}$. Ishii/17/ as well as $\mathrm{T}$. Matsuda et al. /18/ had already mentioned the strong effect of the deposition conditions of $\mathrm{BN}$ (e.g. temperature and pressure) on $\mathrm{d}_{002}$ and $\mathrm{L}_{\mathrm{C}}$, their data being in good agreement with those given in table 2.

The analysis of the fine structures of the EELS spectra and more particularly those occuring after the ionization edge of a given element (EXELFS) can be used to derive its atomic surrounding /13/. However, in the case of Boron Nitride due to the poor distance between the Boron and Nitrogen $\mathrm{K}$ edges (188 eV and $400 \mathrm{eV}$ respectively fig 2), the EXELFS analysis is limited to the first and second neighbors /19/. The interatomic distance B-N, B$B$ and $N-B, N-N$ deduced from the EXELFS treatment (fig 5-6), for the BN films deposited from $\mathrm{BF}_{3}-\mathrm{NH}_{3}$ under CVI conditions are given in table 3. They are close to the values which are known for hex-BN /20/. The mean BNB angle can be evaluated at $123^{\circ}$. It is close to $120^{\circ}$ characteristic of $\mathrm{sp}^{2}$ atomic orbital hybridation. Those results confirm that Boron-Nitrogen local ordering is an almost perfect hexagon.

The theoretical density of the BN deposit has been calculated on the basis of the EXELFS and diffraction data. As expected, it has been found to be significantly lower than that of well ordered hex-BN (i.e. 2.07 and $2.27 \mathrm{~g} . \mathrm{cm}^{-3}$, respectively). From the measured value (i.e. 1.6 to $1.9 \mathrm{~g} \cdot \mathrm{cm}^{-3}$ ), the porosity of the $\mathrm{BN}$ film deposited under CVI-conditions, was estimated to be of $8-22 \%$. This range of porosity corresponds to a low density BN according to the classification proposed by $\mathrm{T}$. Matsuda et al. $\left(=1.5-1.9 \mathrm{~g} \cdot \mathrm{cm}^{-3} ; \mathrm{Vp}=4\right.$ $-30 \%) / 21 /$. 


\section{3- BN deposition mode1}

According to $\mathrm{T}$. Matsuda et al./21/, polymeric atom clusters are formed in the gas phase near the substrate. When these clusters are adsorbed on the hot substrate surface, they undergo a thermal decomposition. When the amount of clusters is too high, a long range ordering of the boron and nitrogen atoms is no longer kinetically possible and the deposit is made of randomly orientated stacks of BN layers and of pores (low density BN deposits) /21/. It is noteworthy that L.E..Boravitch et al. have suggested that $\mathrm{B}_{3} \mathrm{~N}_{3} \mathrm{H}_{3} \mathrm{Cl}_{3}$ clusters could be formed in the vapor phase prior to the adsorption and surface reaction (i.e. thermal decomposition with an evolution of $\mathrm{HCl}$ and incorporation of the boron and nitrogen atoms to the deposit) steps $/ 22 /$.

It is suggested that similar polymeric clusters could be formed from $\mathrm{BF}_{3} / \mathrm{NH}_{3}$ in the vapor phase, adsorbed on the hot substrate and decomposed, thus explaining the different microstructures which have been observed in the BN deposit. In such a model, the alignment of the BN layers in the close vicinity of the fiber surface could be the result of (i) a low concentration of clusters within the interval of the fiber preform at the beginning of the infiltration process which is consistant with a low deposition rate /23/ and (ii) a substrate effect $/ 24 /$, thus allowing kinetically the ordering of the hexagonal B-N first layers. Later on, when a steady state is reached, the number of clusters in the vapor phase within the intervals of the preform is thought to be higher with the result that: (i) an ordering of the B-N layers is no longer kinetically possible and (ii) the microstructure of the BN deposit becomes random with numerous micropores.

\section{CONCLUSION}

On the basis of complementary analytical methods (i.e. AES, XPS, TEM, XRD), the composition, crystal texture and microstructure of BN films deposited from $\mathrm{BF}_{3}-\mathrm{NH}_{3}$ mixtures under CVI-conditions, have been characterized. The deposits are non-stoichiometric (excess of boron with respect to $\mathrm{N}: \mathrm{B}=1$ atomic ratio) and contain a significant amount of oxygen. Despite this contamination by oxygen, the basic structural unit seems to be an almost perfect hexagonal ring. The crystal structure based on hexagonal layers is turbostrastic. The microstructure is similer to that of a pyrocarbon deposited at low temperature. It is characterized by submicroscopic pores and stacks of BN-layers which are randomly orientated in the bulk and parallel to the fibers in the close vicinity of the fiber-interphase boundary.

The authors thank M. Monthioux (Laboratoire Marcel Mathieu - Pau) for his advice.

\section{REFERENCES}

/1/ S.P.S. Arya and A. D'amico, Thin Solid Films, 157 (1988) 267

/2/ H. Hannache, R. Naslain and C. Bernard, J. Less-common Met., 95 (1983) 221

/3/ H. Hannache, J.M. Quenisset, R. Naslain and L. Heraud, J. Mater. Sci., 19 (1984) 202

/4/ H.o. Pierson, J. Composite Mater., 9 (1975) 828

$15 /$ J.J. Gebhart, Proc. 4th Int. Conf. CVD (Boston, Oct. 8-11, 1973). The Electrochem. Soc., Princeton, NJ, (1973) 460 (extended abstract)

/6/ G. Lacrambe, Thesis : Fabrication et "Graphitation" du Nitrure de Bore obtenu par dépôt chimique en phase vapeur en basse temperature, University of Bordeaux-I, 1988

/7/ L. Grateau, N. Lob and M. Parlier, Int. Conf. Canterbury, U.K., 1987, 14 th Vol Science of Ceramics ed. D. Taylor, Institute of Ceramics. U.K. (to be published)

/8/ M.H. Rawlings, J.A. Nolan, D.P. Stinton and R.A. Lowden, Proc. MRS Symp. "Advanced Structural Ceramics", 78 (1986) 223

/9/ J.G. Thébault, F. Patent 2567874 Jul.20, 1984

/10/ R.W. Rice, U.S. Pat. 4, 642, 271, Feb. 10, 1987

/11/ B. Bender, A. Shadwell, C. Bulik, L. Incovarti and D. Lewis, Amer. Ceram. Soc. Bull., $65 / 2(1986) 363$

/12/ R.N .Singh and M.K .Brun, Advanced Ceram. 3/3 (1988) 235

/13/ R.D. Leapman, L.A. Grunes, P.L. Fejes, J. Silcox, EXAFS Spectroscopy. Eds B.K. Teo and

D.C. Joy (Plenum 1981) p. 217

/14/ V.G. Aleshin, A.N. Sokolov, M.G. Gudinov and A.H. Shulzhenko, Porosh. Metal.12 (1986) 76

/15/ J. Goma, Thesis : Pyrocarbones et Interfaces Silicium Carbone. Etude en Microscopie et Diffraction Electroniques, University of Orleans, 1983

/16/ J. Goma and A. Oberlin, Thin Solid Films, 65 (1980) 221 
/17/ H. Tagawa and K. Ishii, J. Electrochem. Soc. Japan, 35 (1967) 43

/18/ T. Matsuda, N. Uno, H. Nakae and T. Hirai, J. Mater. Sci., 21 (1986) 849

/19/ J.M. Martin, M. Belin, J.L. Mansot, K. Hssein, G. Zanchi and J. Sevely Inst. Phys.

Conf. Ser., $\mathrm{N}^{\circ}$ 93, Eurem 88, York, England (1988) 175

/20/ A.P. Stephens and L.M. Brown UMIST/Manchester (1981) 152

/21/ T. Matsuda, H. Nakae and T. Hirai, J. Mater. Sci., 23 (1988) 509

/22/ L.E. Boravitch, M.L. Long and W.P. Fitzpatrick, A.D. Report 733292, 1971

/23/ Y. Yoshimoto, T. Suzuki, Y. Higashigaki and S. Nakajima, Thin Solid Films 162 (1988)

273

/24/W. Kowbel and J. Don, J. Mater. Sci. 24 (1989) 133.

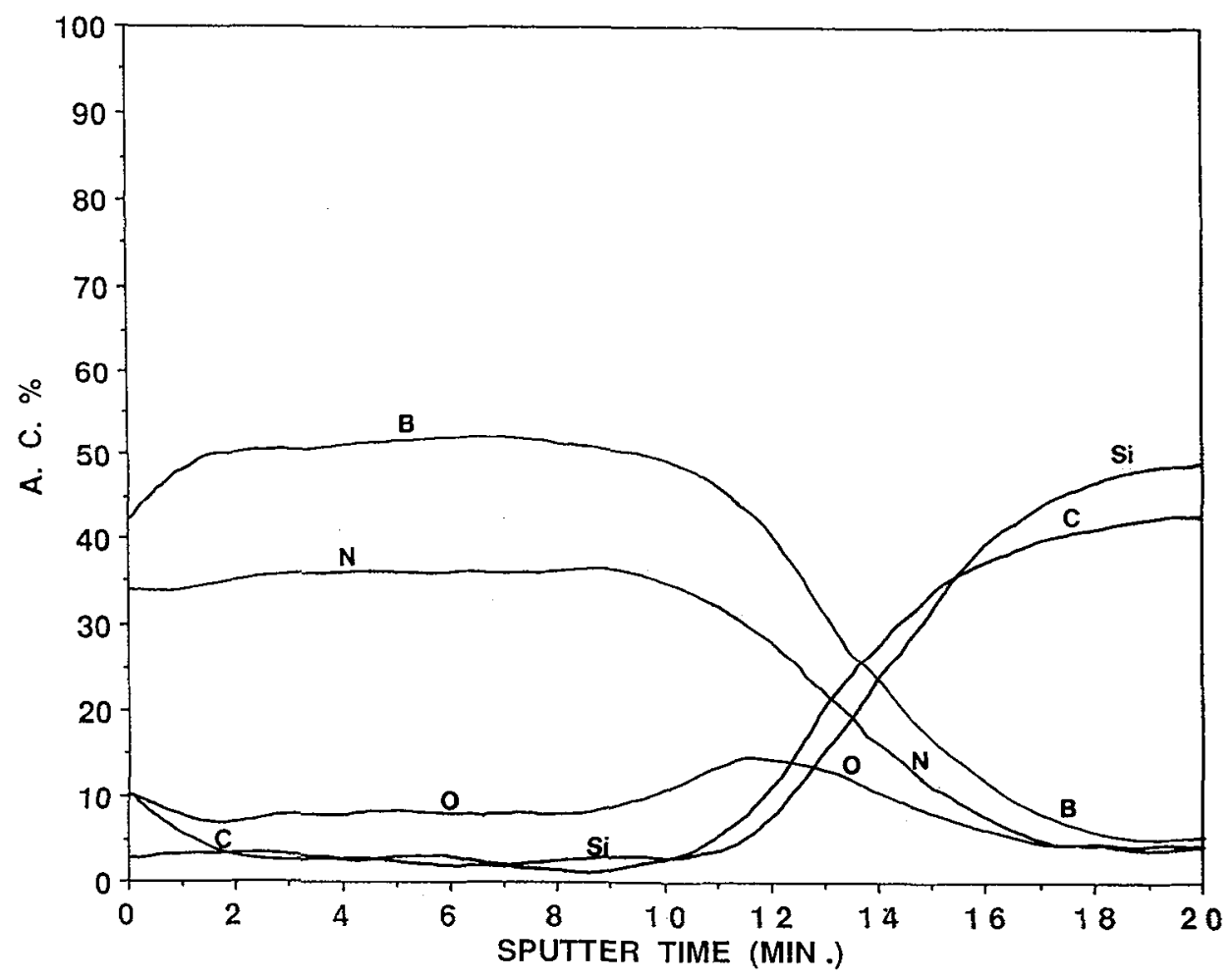

Fig 1 : AES depth profiles for boron (B-KLL), nitrogen (N-KLL), oxygen (O-KLL), silicon (Si-LVV) and carbon (C-KLL) recorded through a BN-film deposited. on a plane SiC-sintered substrate (BN sputtering rate : $9 \AA$. $\min ^{-1}$ ).

Table 1 : Composition of pyro-BN deposited on plane SiC sintered substrates or $\mathrm{SiC}$ (Nicalon) fiber within a porous preform, from $\mathrm{BF}_{3}-\mathrm{NH}_{3}$ mixtures

\begin{tabular}{|c|l|l|c|}
\hline Analyses & Materials & $\mathrm{N}: \mathrm{B}$ at. ratio & $0: \mathrm{B}$ at. ratio \\
\hline AES & $\begin{array}{l}\text { plane SiC substrate } \\
\text { SiC fiber }\end{array}$ & $\begin{array}{l}0.6-0.7 \\
0.7\end{array}$ & $\begin{array}{l}0.2 \\
0.2\end{array}$ \\
\hline \multirow{2}{*}{ EELS } & SiC fiber & $0.7-0.8$ & $0.1-0.2$ \\
\hline XPS & plane SiC substrate & $\begin{array}{l}0.6-0.7 \\
0.67\end{array}$ & $\begin{array}{l}0.2 \\
0.27\end{array}$ \\
\hline
\end{tabular}




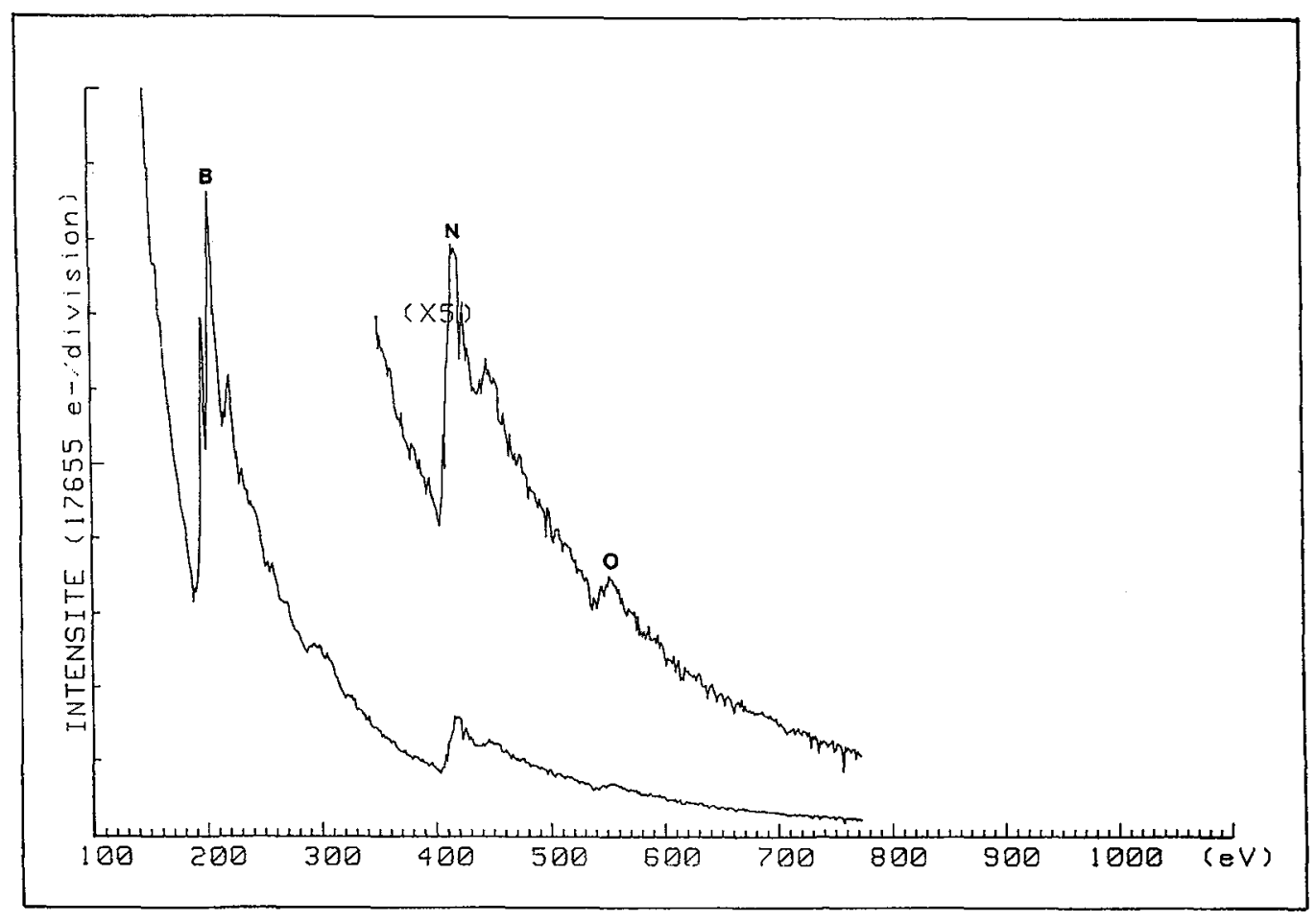

Fig 2 : EELS spectrum of Boron Nitride

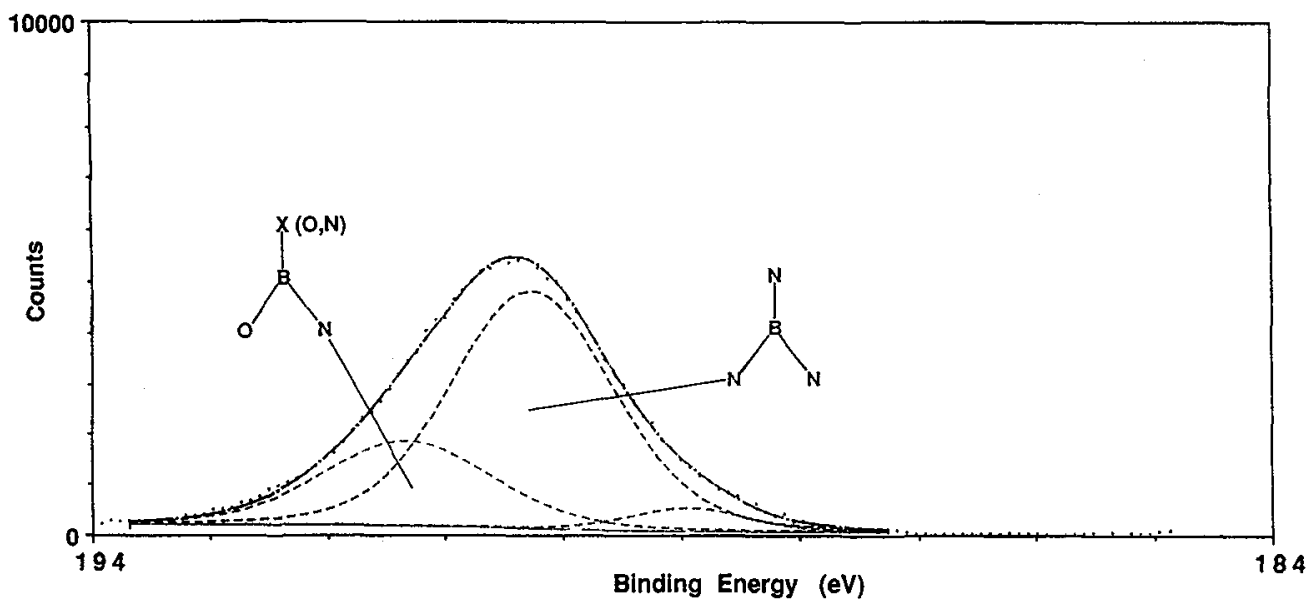

Fig 3 : Deconvolution of the B 1s XPS peak for BN deposited on a SiC substrate from a $\mathrm{BF}_{3}-\mathrm{NH}_{3}$ mixture under CVI conditions. 


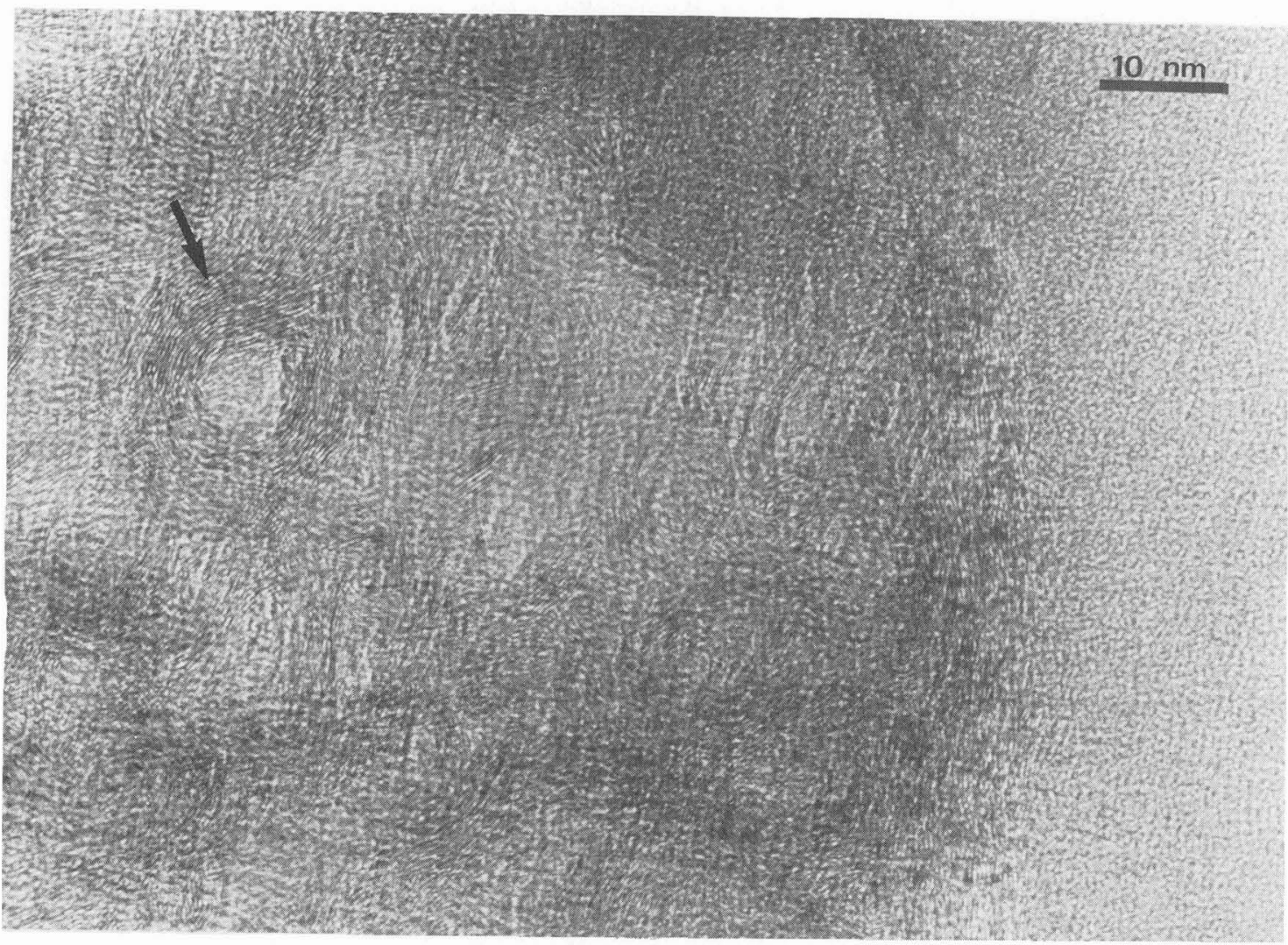

(a)

Random layers

$\mathrm{BN}$
Aligned layers

FIBER

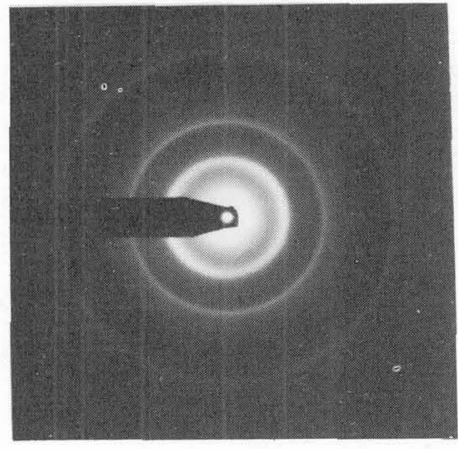

(b)

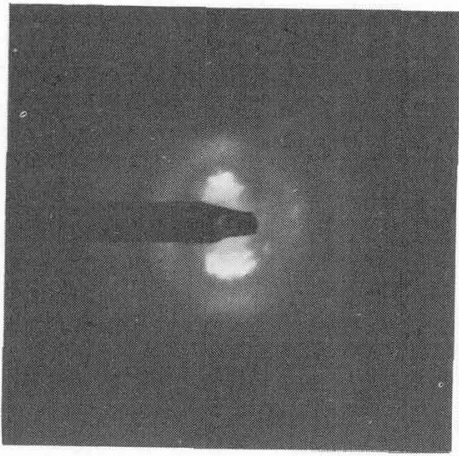

(c)

Fig 4 : TEM analysis of BN deposited within a porous preform on a S1C (Nicalon) fiber : (a) bright field image of the microtexture (a micropore is shown by an arrow), (b)diffraction pattern of the BN deposit far from the fiber surface and (c) microdiffraction pattern (STEM configuration) of the aligned BN layers near the fiber surface. 
Table 2 : Crystallographic spacings and $\mathrm{L}_{c}$ values for pyro-BN as obtained from electron and $X$-ray diffraction (data for hex-BN are given for the purpose of comparison)

\begin{tabular}{|l|l|c|c|c|c|}
\hline $\begin{array}{c}\text { Material } \\
\text { (Method) }\end{array}$ & $\begin{array}{l}\mathrm{d}_{\mathrm{OO} 2} \\
(\AA)\end{array}$ & $\begin{array}{c}\mathrm{d}_{10} \\
(\AA)\end{array}$ & $\begin{array}{c}\mathrm{d}_{11} \\
(\AA)\end{array}$ & $\begin{array}{c}\mathrm{d}_{20} \\
(\AA)\end{array}$ & $\begin{array}{c}\mathrm{L}_{\mathrm{f}} \\
(\AA)\end{array}$ \\
\hline hex-BN & 3.33 & $2.16(101)$ & $1.25(112)$ & $1.084(202)$ & - \\
\hline $\begin{array}{l}\text { pyro-BN } \\
(\mathrm{TEM})\end{array}$ & 3.65 & 2.12 & 1.23 & 1.07 & 28 \\
\hline $\begin{array}{l}\text { pyro-BN } \\
(\mathrm{XRD})\end{array}$ & 3.63 & 2.14 & - & - & 27 \\
\hline
\end{tabular}

Table 3 : Distances between first neighbors obtained from EXELFS data (uncertainty : $0.02 \AA$ )

\begin{tabular}{|c|c|c|}
\hline Chemical bonds & in hex-BN $(\AA)$ & in pyro-BN $(\AA)$ \\
\hline N - B & 1.446 & 1.44 \\
B - N & & 144 \\
N - N & 2.504 & 2.55 \\
B - B & & 2.52 \\
\hline
\end{tabular}




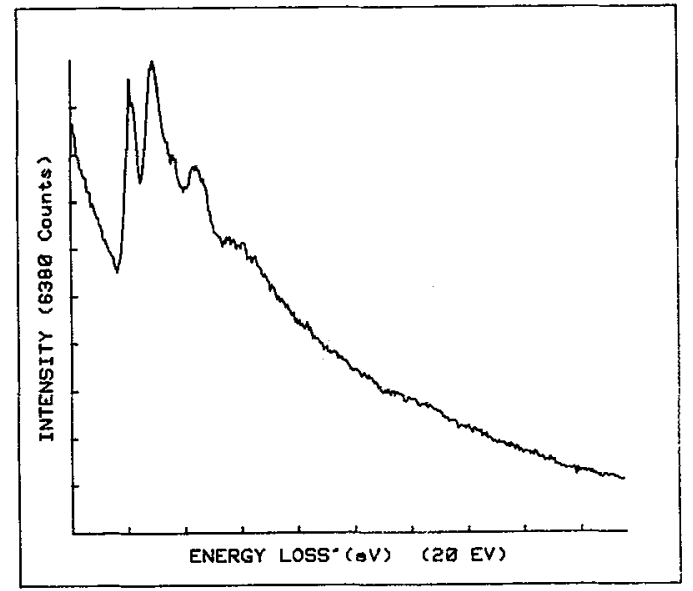

(a)

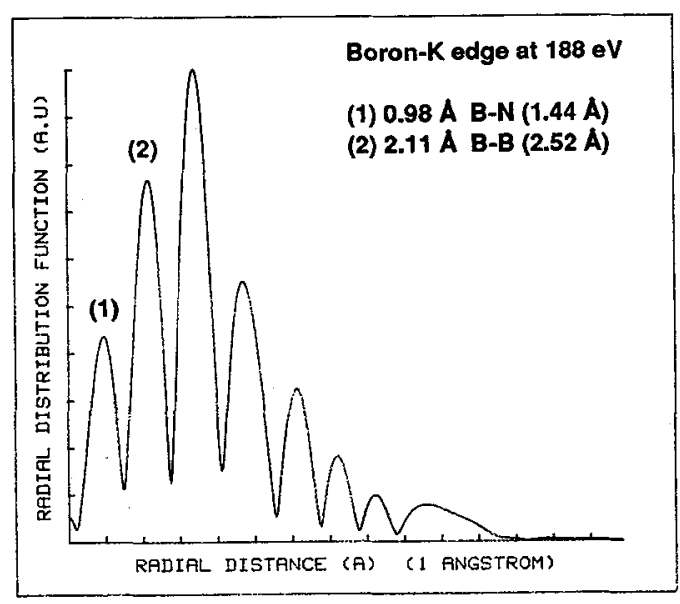

(b)

Fig 5(a) : Magnitude of the Boron $\mathrm{K}$ edge with the EXELFS modulation

(b) : Radial distribution fonction deduced from the spectra (a) (the data are not corrected for the phase shift)

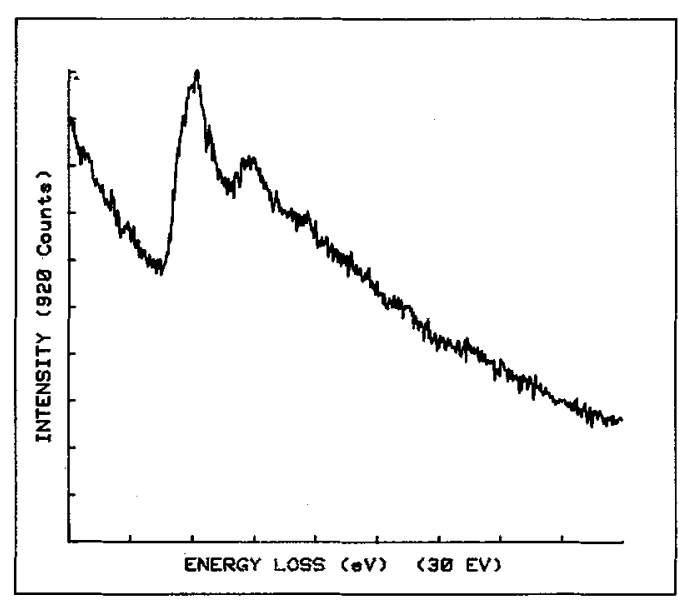

(a)

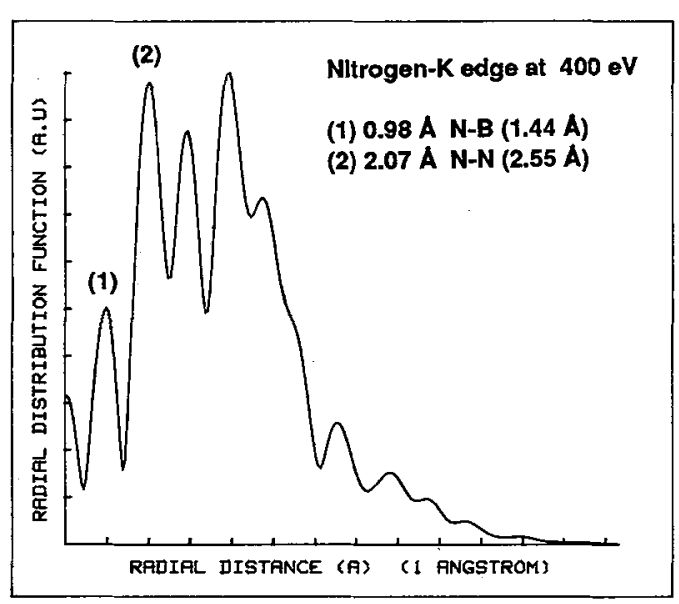

(b)

Fig 6(a) : Magnitude of the Nitrogen $\mathrm{K}$ edge with the EXELFS modulation

(b) : Radial distribution fonction deduced from the spectra (a) (the data are not corrected for the phase shift) 